\title{
La tecnología y el estructuralismo económico
}

\author{
Manuel Alejandro Rayran Cortés*
}

\section{RESUMEN}

La disciplina de las relaciones internacionales cumple un siglo de haber sido fundada. El avance tecnológico y los cambios dentro de la vida internacional han llevado a reflexionar sobre su impacto en el funcionamiento del sistema internacional y sus consecuencias. El materialismo dialéctico permite comprender este nuevo elemento y su resultado en las dinámicas internacionales, el cual es considerable, pues si bien es cierto que atrae nuevos avances para los individuos, el comercio y las comunicaciones, también acrecienta la desigualdad ya existente entre los Estados y fortalece la división estructural entre ellos.

Palabras clave: tecnología, estructuralismo económico, materialismo dialéctico, Immanuel Wallerstein

\section{Technology and economic structuralism}

\section{ABSTRACT}

The discipline of international relations is in its 100th anniversary. Technological progress and changes have impacted the functioning of the international system. Dialectic materialism allows us to understand this new element and its consequences in international dynamics, which are considerable. Although it generates positive outcomes for people, commerce and communications, it also increases the inequality that already exists between States, and strengthens the structural division between them.

Key words: technology, economics structuralism, dialectic materialism, Immanuel Wallerstein

* Magíster en ciencia política orientación en relaciones internacionales, con especialidad en diplomacia y resolución de conflictos, Universidad Católica de Lovaina. Docente de la Facultad Gobierno y Relaciones Internacionales, Universidad Externado de Colombia, Bogotá (Colombia). [manuel.rayran@uexternado.edu.co]; [https://orcid. org/0000-0003-3658-2690].

Recibido: 1 de diciembre de 2019 / Modificado: 31 de enero de 2020 / Aceptado: 28 de febrero de 2020

Para citar este documento:

Rayran Cortés, M.A. (2020). La tecnología y el estructuralismo económico. OASIS, 32, pp. 85-104.

Dor: https://doi.org/10.18601/16577558.n32.07 


\section{INTRODUCCIÓN}

Durante los últimos años, las teorías de las relaciones internacionales, concentradas en tres escuelas: neorrealismo, liberalismo y constructivismo, y cuyos máximos exponentes son Kenneth Waltz, Robert Keohane, y Alexander Wendt ${ }^{1}$ (Mearsheimer \& Walt, 2013), han sido confrontadas por no lograr explicar de manera integral los fenómenos sociales que la humanidad ha enfrentado con el arribo de la tecnología, la profunda integración de la economía capitalista, el fortalecimiento de los actores no estatales, la inteligencia artificial, la economía digital, el cambio climático, el incremento en la desigualdad por la mala redistribución de la riqueza y la competencia cada vez más aguda entre el hombre-robot. Esta situación ha obligado a que profesores y estudiantes de la materia replanteen las hipótesis y supuestos que han prevalecido durante los siglos xx y xxI.

Aunque para muchos la crisis con las teorías de las relaciones internacionales es preocupante, para otros es una fase normal que experimenta toda ciencia, más aun, cuando la humanidad se enfrenta a cambios estructurales de índole social, político y económico. Por ende, es el momento más idóneo para abrir el debate y repensar los paradigmas, con el fin de precisar su objeto de estudio, epistemología y las categorías que permitan entender mejor la realidad en la que vive la humanidad. Asimismo, hay que recordar que la disciplina de las relaciones internacionales es muy reciente, si se compara con las ciencias naturales o exactas. Esta "nace" el 30 de mayo de 1919, cuando las delegaciones inglesas y estadounidenses, luego de la primera guerra mundial, fundan las instituciones de investigación en esta área, siendo las más reconocidas el Royal Institute of International Affairs y el Council of Foreign Relations respectivamente (Krippendorff, 1985).

En ese sentido, el presente trabajo se erige como un primer acercamiento académico-investigativo para comprender mejor las relaciones internacionales, utilizando componentes teóricos que no son precisamente nuevos pero que sí incluyen nuevos elementos o categorías que determinan la realidad del actual orden mundial. De ahí que las preguntas que direccionarán la reflexión de este capítulo son: ¿cuál es el objeto de estudio de las relaciones internacionales? y ¿cómo se podría comprender el funcionamiento del sistema internacional con los nuevos cambios del siglo xxI, en específico con la tecnología? Si bien el primer cuestionamiento ha estado presente durante los tres debates interparadigmáticos, se considera que es necesario plantearse nuevamente estos interrogantes por el ingreso de nuevos fenómenos en la vida internacional, como es la tecnología, razón por la que se plantea el segundo interrogante.

1 En 2009, Teaching, Research, and International Policy (TRIP) elaboró una encuesta para que las facultades de relaciones internacionales de diez países (Australia, Canadá, Irlanda, Israel, Hong Kong, Nueva Zelanda, Singapur, Sudáfrica, Reino Unido y Estados Unidos) respondieran, con el fin de saber cuál es la variación que existe en cada país sobre las escuelas de relaciones internacionales, qué piensan sobre las escuelas, observar la importancia del proceso en la política y el enfoque crítico sobre los debates de política exterior. 
Para responder los anteriores cuestionamientos, se plantea la siguiente hipótesis: el objeto de investigación de las relaciones internacionales es el estudio de la vida internacional ${ }^{2}$ (Duroselle, 2018) que está configurada por los datos esenciales emanados por las ciencias sociales, los que permiten identificar y distinguir con claridad los elementos accidentales que impactan el comportamiento de los agentes del orden internacional como, por ejemplo, la tecnología. Este enfoque, además, permite analizar las situaciones a partir de dos perspectivas, la primera desde el sistema complejo del ser humano estudiado por las ciencias sociales $y$, el segundo, por la dialéctica materialista que se centra en investigar el movimiento y la esencia de los fenómenos que los individuos experimentan. Los anteriores elementos se aplicarán al impacto del desarrollo tecnológico del siglo Xxi en la configuración del orden internacional señalado por Wallerstein conocido como el estructuralismo económico.

De igual manera, con el fin de entender el sistema complejo del ser humano, antes mencionado, es necesario tener en cuenta un abanico multidisciplinar de las ciencias sociales, de ahí que se utilicen ciencias auxiliares generales y parciales, siendo la primera todas aquellas que ofrecen conceptos, métodos y explicaciones como la historia, la economía, la ciencia política, entre otras; y la segunda las que están delimitadas en áreas concretas como la estrategia militar, la geografía, las ciencias militares, etcétera (Cervera, 1991).

Con el objetivo de profundizar en los temas antes citados se inicia con una explicación epistemológica y ontológica para comprender los fenómenos sociales, para luego continuar con una exposición del estructuralismo económico y el impacto de la tecnología en el orden mundial. Al final, se ofrecerán algunos comentarios finales.

\section{ELEMENTOS EPISTEMOLÓGICOS Y ONTOLÓGICOS}

Los conflictos sociales han estado presentes desde que el hombre comenzó a vivir en sociedad con sus pares, resolviendo estos a través del diálogo o con acciones bélicas (Greene, 2018). Con el avance de la ciencia en distintos ámbitos de la realidad y la amplitud de las redes comerciales, estas diferencias tuvieron mayor magnitud y consecuencias en la vida organizada del hombre; es decir, en las sociedades. Sin embargo, y a pesar de que este fenómeno siempre estuvo presente en la historia del hombre, la humanidad tomó conciencia de la importancia de estudiar los conflictos de carácter internacional desde un enfoque científico

\footnotetext{
2 La tendencia del mainstream de las teorías de las relaciones internacionales es estudiar los fenómenos que estén referenciados con las relaciones de un Estado hacia otro. No obstante, esta categorización de análisis es reduccionista ya que no reconoce a otros actores del sistema internacional que tienen injerencia en él, lo que permitiría solo hablar de política exterior. En ese sentido, Duroselle (2018) considera que para examinar las relaciones de todos los grupos que componen el sistema internacional es mejor abordarlo desde la vida internacional que, en últimas, constituyen las relaciones internacionales.
} 
luego de dos guerras mundiales y sus consecuencias en el humano. En ese sentido, docentes, estudiantes y personas apasionados por la vida internacional se han cuestionado dos elementos esenciales: ¿qué parcela de la realidad social y objeto material explican las relaciones internacionales? y, ¿cómo se debe analizar esta?

\subsection{Elementos epistemológicos}

El hombre está inmerso en un complejo sistema interconectado por grupos sociales, Estados, multinacionales de servicios y mercancías, grupos terroristas, bancos, organizaciones no gubernamentales, organizaciones intergubernamentales, grandes conglomerados de la información, entre otros actores, que interactúan entre ellos de manera constante y en un tiempo y espacio más reducido gracias a los avances tecnológicos. De esta manera, para comprender mejor el modo como funcionan sus interacciones, es preciso analizar a profundidad las relaciones que entre ellos se establecen, qué condiciones determinan esas conexiones y el porqué estos actores entran en conflicto o en cooperación.

El enfoque que permitiría estudiar los anteriores componentes es el materialismo dialéctico, ya que se encuentra en la investigación práctica de los fenómenos individuales, naturales y sociales. Para mayor comprensión de cada elemento de esta corriente de pensamiento, se desagregará y luego se materializará en las relaciones internacionales. La realidad es un sistema complejo que está compuesto por un alto número de elementos materiales que interactúan entre ellos debido a unas fuerzas que los ponen en contacto, creando una relación dialéctica. Esta última es una categoría de suma importancia ya que, como lo afirma Ulises Casas Jerez (2007, p. 333), esta

(...) expresa la interconexión dinámica de las cosas, la universalidad del cambio y su carácter radical: todo lo que posee realidad de alguna clase se encuentra en proceso de transformación, por el hecho de que consta de factores o fuerzas opuestas, el movimiento interno de las cuales lo conecta todo y cambia toda cosa en algo distinto.

En consecuencia, todos los agentes del sistema están en constante interacción debido a que entre ellas hay contradicciones, lo que crea un desplazamiento continuo que conduce al cambio, permitiendo resolver la discordancia por su propia dinámica, pero creando otras condiciones para una nueva puja. Este proceso cíclico configura la triada dialéctica hegeliana que está compuesta por la tesis, antítesis y síntesis. Ahora bien, ese choque entre los componentes se exterioriza en fenómenos de manera particular que el humano, en una primera instancia, lo identifica a través de los datos de los sentidos (Russell, 1953), pero que posteriormente, con el fin de discernir la esencia del fenómeno, de manera consciente y a través del método científico, el hombre comprende las causas y las consecuencias del fenómeno observado ${ }^{3}$. Por

3 Gary King, Robert Keohane y Sydney Verba (2000) en su libro El diseño de la investigación social. La inferencia científica en los estudios cualitativos, plantean un modelo de investigación para diseñar leyes en el 
otra parte, con el fin de diseccionar el fenómeno y estudiar los elementos que lo componen y las fuerzas que a estos los oponen, es necesario estudiar la manifestación en la dirección de lo general a lo particular e identificar lo cualitativo y cuantitativo en esa relación dialéctica y de transformación (Jerez, 2007).

El principal objetivo de la ciencia en general es explicar la realidad ${ }^{4}$; es decir, demostrar las razones que originan los fenómenos que el hombre observa y le perjudican, pues hay que recordar que el ser humano es un objeto de las leyes de la naturaleza de la que hace parte y de la sociedad a la que pertenece. Por consiguiente, todo fenómeno tiene unas circunstancias, espacio, tiempo y elementos precisos que generan las manifestaciones y consecuencias para los componentes involucrados y para el sistema en general que tenga relación con ese fenómeno. En ese sentido, es necesario revisar todos los elementos que tienen incidencia en el proceso y, en consecuencia, es necesario el uso de conceptos de grandes teorías y teorías de medio rango, permitiendo crear una estructura mental en las relaciones internacionales (Holsti K., 1983).

Con base en lo anterior, la realidad del sistema internacional se analiza a partir de la complejidad político-social, y como un todo y no por partes separadas, siendo el sistema productivo y la historia los mejores mecanismos para comprender las ciencias sociales porque estos no solo están enfocados en el pasado sino también en el proceso continuo del cambio de la historia (Cox, 1981). Es por ello que investigar la vida internacional a partir de un enfoque dinámico es lo que hace considerar esta corriente como crítica dentro de las teorías de las relaciones internacionales, a diferencia del realismo y el liberalismo que observan los hechos mundiales como pinturas estáticas (Arenal, 1989; Cox, 1981; Krippendorff, 1985).

Ahora bien, con respecto al sistema productivo, este se puede catalogar como la fuerza que hace que el hombre y sus grupos organizados crean, mantengan o destruyan sus relaciones asimétricas de acuerdo con los momentos históricos y con los desarrollos científicos de cada época, en otras palabras, la estructura económica define en cierto grado la historia y el devenir de las sociedades. La historia del hombre se debe tener en cuenta por tres razones que expresa Raymond Aron (1996): a) el hombre es histórico; es decir, un ser social, b) la socialización del humano está enmarcada por su tiempo y por el pasado, y c) el hombre

\footnotetext{
campo de las ciencias sociales, entre las cuales se mencionan cinco reglas para elaborar teorías causales: elaborar teorías falsables, construir teorías que tengan coherencia interna, seleccionar cuidadosamente las variables dependientes, maximizar lo concreto y formular teorías de forma tan incluyentes como sea posible.

4 Bertrand Russell (1953) en su libro Problemas de la filosofía, discute sobre la realidad y la apariencia de los fenómenos que el ser humano experimenta en su vida. En él, Russell, luego de una larga reflexión filosófica, considera que se pueden estudiar los fenómenos a partir de la creencia “institutiva” que hace referencia al razonamiento lógico que va más allá de los datos de los sentidos. En el marco de lo anterior, se puede considerar una realidad cuando: 1) los seres humanos tienen una necesidad del fenómeno y 2) el fenómeno es permanente y sostiene o causa los datos de los sentidos de las personas en el tiempo estudiado.
} 
es histórico porque tiene la capacidad de pensar su pasado y tratar de orientar un porvenir.

Entonces, el ser humano es un animal social que, resultado de un largo proceso evolutivo y para garantizar su supervivencia, ha creado formas novedosas de comunicación, cooperación, coordinación de acciones e incluso ha construido herramientas para mantener la disciplina de sus sociedades (Greene, 2018). Su conducta social está enmarcada por un mundo material e inmaterial que obedece a un desarrollo de las fuerzas materiales económicas. Así pues, para comprender la actual situación del sistema internacional es necesario revisar la relación económica que existe entre todos los actores, cuál es su nivel de asimetría entre ellos y qué elementos hacen que su conexión sea desigual. Es claro que, tal objetivo es de gran envergadura y ambicioso, y más en la actualidad, en la medida que el sistema productivo capitalista está cada vez más integrado a la rama financiera y tecnológica.

\subsection{Elementos ontológicos}

El sistema internacional está establecido, regulado y sostenido a través de las normas que los Estados han creado y que otros actores respetan y legitiman, a pesar de que -en ocasiones- traten de modificarlas. Estas normas, que son de carácter social, han sido creadas por los humanos y sus colectivos que, de manera consciente, buscan regular sus relaciones sociales que están determinadas por las fuerzas productivas. Este planteamiento dista de las concepciones idealistas (Jerez, 2007) que sostienen que las formas del desarrollo social obedecen a una voluntad inmaterial que puede regular el comportamiento de los individuos de la comunidad, verbigracia: un "contrato social" o una "mano invisible", que hacen parte intrínseca del capitalismo y fundamentan la creación del Estado y su función dentro del sistema productivo 5 .

No obstante, en el transcurso del desarrollo de las sociedades y, de manera frecuente, el hecho económico ha tenido un papel fundamental porque es capaz de limitar el comportamiento del individuo. En ese sentido, de la interacción económica entre los individuos, se concreta la costumbre, que después se materializa de forma escrita con el fin de reglamentar el hecho económico como resultado de la interacción social (Jerez, 2007). Lo antes

5 A finales del siglo XVIII con la revolución francesa y durante todo el siglo XIX, el liberalismo económico y político permitió que la burguesía llegara al Estado, desplazando así del poder a los reyes y amalgamando esta organización política a sus intereses y beneficios. Esta situación la evidencia el sociólogo Max Weber, quien en sus escritos afirma que el Estado significa "(...) la transferencia de la empresa capitalista a la política. El Estado es tratado como si consistiera única y exclusivamente en empresarios capitalistas". Asimismo, el historiador Otto Hintze sostiene que el capitalismo "no es otra cosa que la faceta económica de los Estados y pueblos modernos. Su teoría incluye la razón económica además de la de Estado. Sus etapas coinciden con las de la política imperialista estatal. Está vinculado, venga lo que viniere, con el moderno sistema de Estados y su política” (Krippendorff, 1985, p. 66). Las funciones que le otorgaron estos dos conceptos al Estado, como organización social y política sui generis, se pueden resumir en: delimitar la exclusividad de un territorio, fortalecer el modo de producción capitalista y la pacificación interna de los países. 
explicado se evidencia, por ejemplo, con el derecho económico que apareció años después de la práctica comercial tribal del hombre y que, con el tiempo, se perfeccionó y amplió por la extensión del comercio. Un segundo ejemplo es la conformación de los sistemas políticos, los cuales son moldeados según el sistema productivo que se implemente, así, si es el capitalismo la jurisprudencia privilegiará la propiedad privada, caso distinto si se aplica el comunismo, el cual buscará eliminarla.

Así pues, para comprender el entramado internacional es necesario estudiar la configuración económica de cada país, en la que comprenda las ventajas y desventajas de los sectores productivos, alimenticios y de servicios, la inversión en la ciencia, la creación de la riqueza, entre otros elementos de importancia que ayuden a definir las herramientas que tienen los agentes para negociar, generar influencia y lograr sus objetivos dentro del entramado mundial.

De igual manera, revisar la relación entre los actores desde la economía facilitará comprender las dinámicas del sistema internacional no solo porque evidencia la manera como el hecho económico determina el comportamiento de los agentes; sino también por dos razones: Primero, desde hace varias décadas, el capitalismo, cuyo objetivo es la reproducción del capital y su acumulación, se impuso como el sistema productivo común de la vida internacional gracias a la ampliación de las redes comerciales y la profundidad de los servicios financieros en otros sectores de la economía. Verbigracia, los acuerdos económicos regionales, los tratados de libre comercio y la incorporación de otros sectores económicos y sociales a lo financiero, como son los commodities del sector agropecuario o la conversión de lo público a lo privado como la salud, las pensiones y la educación.

Segundo, el prototipo de vida individual instaurado por el capitalismo concibió un modelo propio para asignarle poder a ciertos elementos que logran determinar las relaciones humanas, verbigracia la riqueza y la propiedad privada. Ahora bien, por poder se comprenderá como la capacidad que tiene un actor para conseguir muchas cosas en un tiempo dado por su posición social (Barry Barnes, 1990). Adicional a esta interpretación, está la del sociólogo alemán Talcott Parsons, citado por Barnes (1990), quien considera el poder como “(...) mecanismo específico que opera para producir cambios en la acción de otras unidades, individuales o colectivas, en los procesos de interacción social" (p. 33). En consecuencia, el poder no es unidireccional, sino que está distribuido entre las diferentes personas y que es claramente asimétrico, relación que abre la opción en la que a pesar de que un actor pueda tener más poder que otro, eso no evita que el actor inferior pueda tener alguna incidencia sobre el poderoso, aunque el que tenga más tendrá mayores oportunidades de conseguir sus metas (Holsti K., 1964).

Ahora bien, lo económico toma un papel preponderante en el poder ya que el dinero encarna la cualidad para asegurar la propiedad privada, base del modelo económico actual, aumentando así la capacidad de influencia del actor dentro del orden político y social. En el presente orden mundial, el poder económico se ha trasladado progresivamente a los sectores financiero y tecnológico, y cuyos propietarios 
gozan del privilegio de configurar las esferas políticas y sociales ${ }^{6}$. Ejemplo de ello son los conglomerados de la información tales como Google, Amazon, Facebook, Instagram, Twitter, entre otros ${ }^{7}$. Por eso, y con base en las anteriores explicaciones, se puede comprender por qué es tan importante estudiar la estructura económica del sistema internacional, ya que permitirá evidenciar qué países tienen mayores capacidades para lograr sus intereses.

\section{EL ESTRUCTURALISMO ECONÓMICO EN EL SIGLO XXI}

\subsection{El sistema mundo de Immanuel Wallerstein}

Para explicar el funcionamiento del sistema productivo y su incidencia en la organización del sistema internacional, es necesario profundizar sobre el capitalismo, el cual se estableció -desde los inicios del siglo xx- cuando se desarrolló en su máxima plenitud a nivel global y relegó los sistemas económicos imperialistas que marcaron el comportamiento de los Estados durante los últimos treinta años del siglo XIx hasta la primera guerra mundial (Taylor \& Flint, 2002; Hobson \& Lenin, 2009).

Como se dijo, el capitalismo tiene por objeto la producción de beneficios y la acumulación del excedente en forma de capital. También se caracteriza por la ausencia de una estructura política dominante y por la libertad que tiene el mercado para determinar la cantidad, el tipo y la ubicación de la producción, la cual lo logra a través de la competencia entre las unidades productivas, interacción que conlleva a que sean pocas las que prosperen y existan en el tiempo porque son las que logran vender más barato en el mercado (Wallerstein, 1999). Ahora bien, como resultado de ese mercado mundial, cuya máxima expresión actual es la globalización, se ha establecido un desarrollo económico desigual en el planeta (Prebisch, 1983). De esta manera, se crea una estructura específica en donde los países, de acuerdo con

6 Henri Landes, en su libro Allô Houston! Les États-Unis vus par un américain en colère, evidencia cómo los sectores financieros y económicos en Estados Unidos han capturado el poder político desde los años 80 a través de los Political Action Committee conocidos como los pac. Para la muestra, las elecciones presidenciales de 2016, en las que Robert Mercer de Renaisssance Technologies 'donó' a los republicanos 16.7 millones de dólares, Thomas Steyer de Next Generation 13 millones de dólares a los demócratas, Kenneth Griffin y Anne Dias de Cita del Investment Group y Global Management 8.5 millones de dólares a los republicanos y George Soros con su fundación 8 millones a los demócratas (Landes, 2016).

7 La fuerza obtenida por los conglomerados de la información no solo se debe a lo económico sino también a lo social. Con lo que respecta a lo primero, por ejemplo, el $1^{\circ}$ de agosto de 2011, Apple sobrepasó por primera vez a la petrolera y gasífera Exxon-Mobil para convertirse en la primera capitalización bursátil del mundo, ya que para esa época, mientras que la compañía de recursos mineros estaba valorizada en 331 mil millones de dólares la segunda estaba en 480 mil millones de dólares (Moscovici, Montebourg, Cahuzac, \& Pellerin, 2013). Respecto al segundo aspecto, los conglomerados de la información se han transformado en herramientas para direccionar el comportamiento entre los seres humanos y las sociedades, así como también de su destino político, verbigracia la información vendida por Facebook a Cambridge Analytica para influir en las votaciones presidenciales estadounidenses en 2016. 
su avance y estructura política y económica, asumen ciertas tareas particulares para que el sistema productivo capitalista funcione.

De este modo, Wallerstein identifica tres conceptos arquitectónicos que permiten comprender esos procesos, a saber: centro, periferia y semiperiferia. El criterio de clasificación de un país en alguna de estas categorías está con base en el proceso económico complejo y la explotación del centro hacia la periferia, más no por su ubicación geográfica en específico. De igual manera, la dependencia no se origina por motivaciones morales ni éticas, sino que esa explotación se produce porque tanto el centro como la periferia tienen dos tipos opuestos de relaciones complejas de producción, y se requiere de estas para que funcione el sistema capitalista.

En el caso de los países de centro, el proceso complejo de producción se caracteriza porque tienen un sistema productivo diversificado, salarios altos, un importante avance tecnológico, una notable inversión en la ciencia y una alta concentración de capital para invertir en nuevos sectores, permitiéndoles con todo esto generar una mayor riqueza y una fuerte capacidad económica. Por el contrario, la periferia se caracteriza por tener una estructura económica de bajos salarios, una tecnología embrionaria y un tipo de producción simple, que en la mayoría de casos se enfoca en el sector primario dejando de lado el desarrollo del valor agregado, lo que genera dependencia de los países desarrollados, de la ayuda internacional y de los bancos internacionales (Taylor \& Flint, 2002).

Sin embargo, el centro y la periferia no terminan de explicar por completo el funciona- miento del sistema capitalista y es por esto que Wallerstein incorpora otra categoría conocida como semiperiferia que se caracteriza por ser dinámica debido a que su proceso complejo de producción combina elementos tanto de centro como de periferia; es decir, que los Estados clasificados en esta escala explotan algunas zonas periféricas, pero que a su vez es explotada por el centro. Estos países, asimismo, tienen una singularidad en su combinación ya que, a pesar de tener un crecimiento económico considerable, asemejándose incluso al centro, sus aspectos políticos y sociales son más parecidos a los de la periferia ya que el régimen político es poco democrático y su nivel de corrupción y de desigualdad son considerablemente negativos. Con base en esta breve explicación sobre la estructuración espacial que ha amalgamado el capitalismo, se plantearán algunos elementos que se deben tener en cuenta para determinar el nivel de dependencia en el siglo xxI.

\subsection{Dependencia del siglo xxI}

\subsubsection{Nuevas inversiones y dependencias}

En la actualidad, el sistema productivo capitalista ha profundizado las tres características de su funcionamiento identificadas por John Hobson y Lenin, a saber: la sobreproducción, el subconsumo y el exceso de capital (Hobson \& Lenin, 2009). Estas tres particularidades se materializaron durante el siglo Xx a través del intercambio desigual entre los países de centro, que exportaban productos de valor agregado ya que tenían el capital para invertir en innovación industrial, y las naciones cuyas exportaciones estaban enfocadas en las mate- 
rias primas, que en muchas ocasiones se hacia sin un progreso técnico de industrialización que pudiera ser distribuido entre todos los grupos y clases sociales como sucedió en América Latina (Prebisch, 1986). Este proceso llevó, según Prebisch (1983), a una crisis estructural del capitalismo que procede de la lógica interna del mismo sistema productivo manifestada en el desequilibrio entre el ritmo de consumo y el ritmo de acumulación de capital productivo, siendo este último direccionado a otras formas productivas, como el sector financiero.

Sin embargo, con el excedente de capital y la desregulación de los mercados financieros se abrieron las puertas para que el sector real se relegara como factor generador de la riqueza y lo reemplazara el sector financiero. Este se materializó en derivados especulativos, dinero plástico y el capital ficticio ${ }^{8}$, los cuales han marcado la economía mundial, durante los últimos decenios (Grosser, 2011). También, tuvo la capacidad de integrar nuevos sectores de la economía al régimen especulativo como, por ejemplo, los productos primarios (conocidos como commodities). De ahí que, durante los últimos treinta años, los países de centro han acumulado un capital importante que les ha permitido poderlo invertir en la periferia o semiperiferia para que, en estos sistemas de producción de menor complejidad, puedan también reproducir y acumular más capital.
Teniendo claro lo anterior, para comprender la dependencia actualmente y la manera como el capitalismo estructura el funcionamiento entre los países de centro, semiperiferia y periferia es necesario analizar la inversión extranjera directa (IED), el origen de salida y la recepción de esta, y los sectores de la economía en los que se invierte. Se hace hincapié en esto último, ya que el desarrollo del capitalismo y su acumulación del capital -para el siglo XXI- se está direccionando a la tecnología que, por su rápida innovación, permite multiplicar la producción, elevar la productividad y reducir los costos, incrementando así la tasa de ganancia y de acumulación. Asimismo, se resalta la informática como mecanismo para multiplicar la moneda de manera incontrolable e independiente del valor real de la producción (Grosser, 2011).

Es lógico que la tecnología ampliará la dependencia de los países periféricos de los de centro, así como también la desigualdad entre estos, ya que los países menos desarrollados no tienen la capacidad económica ni una correlación de fuerzas favorables para ingresar como participantes activos dentro de estos nuevos cambios científicos, económicos y políticos del mundo. Verbigracia, los países donde se está desarrollando la inteligencia artificial, los nuevos avances en temas medicinales como los

8 Rubén Utria Grosser (2011) explica que los derivados especulativos ocultan las pérdidas, las convierten en ganancias y luego las trasladan a nuevas cadenas de compradores en otras regiones del mundo, como sucedió con los créditos subprime que originaron la crisis financiera de 2008. Con respecto al dinero plástico, este puede reproducir el capital a través del consumo y sin respaldo real. Ese capital ficticio es la fase más avanzada a la que ha llegado el capitalismo ya que en tiempo real, pero sin dinero real, hay transacciones de un número considerable de capital ficticio a través de la informática, por ejemplo, los bitcoins. 
nanorobot ${ }^{9}$, la biotecnología, entre otros, son los de centro, ya que estos Estados y sus multinacionales invierten altas sumas de dinero para ganar terreno en estos asuntos y así competir con otras potencias para dictaminar el orden y las reglas del futuro del sistema internacional ${ }^{10}$. En consecuencia, en la medida que estas transformaciones se desenvuelvan con el transcurrir del tiempo, las dinámicas de funcionamiento del sistema productivo capitalista organizarán de nuevo a los países de centro, periferia y semiperiferia de manera asimétrica y de dependencia para que el capital siga siendo el vector transversal y pueda reproducirse y acumularse, intentado así evitar que paralice la producción y el subconsumo (Grosser, 2011).
Lo anterior llevará a que la disparidad del desarrollo entre los países de centro y periferia se amplíe ya que las inversiones necesarias para ingresar a la tecnología son altas, llevando así a que el desarrollo social de las naciones periféricas quede estancado en relación con el avance que experimentarían las sociedades de centro con las innovaciones de la ciencia y la tecnología. Esta situación, además, conduce a controvertir los modelos de desarrollo por etapas o lineal, como el del economista Rostow, quien sostenía que un país puede recorrer la senda del desarrollo en cinco etapas ${ }^{11}$, como se evidencia en la ilustración 1 (Slater, 2011).

9 Los nanorobot son un robot cuyos componentes son minúsculos, están construidos con nanotecnología y sus componentes se caracterizan por tener elementos moleculares o con base en ADN. El avance en esta tecnología es tal que en la actualidad algunos centros médicos y farmacéuticas de los países más desarrollados aspiran a que en unos años los nanorobots puedan transitar por el sistema nervioso identificando enfermedades, eliminando células cancerosas o bacterias. Asimismo, en 2015, los médicos presentaron un tipo de antibiótico nombrado como teixobactina, al cual hasta el momento las bacterias no presentan resistencia. Todo lo descrito se logró con una alta inversión de dinero, como lo hace la compañía norteamericana Google Venture (GV), fondo que busca invertir en nuevos avances tecnológicos (Harari, 2016).

10 Si bien es cierto que la tecnología de la información y de las comunicaciones está concentrada en compañías privadas, se hace un énfasis en el Estado ya que, como Manuel Castells (1996), en su libro La era de la información. Economía, sociedad y cultura, lo menciona, el aparato estatal es fundamental para el desarrollo de la tecnología ya que en últimas puede promover o detener con normatividad la innovación en este sector.

11 Las cinco etapas de Rostow sobre el desarrollo, que tienen como particularidad que es evolutivo y lineal, son: primero, 'la sociedad tradicional', aquella que se centra en una economía agraria, hacia la autosubsistencia, con baja productividad y con una capacidad tecnológica embrionaria. Segundo, las 'condiciones previas al despegue', fase en la que hay un incremento del capital disponible, en especial social fijo, un aumento en la productividad agrícola, así como también un avance en el nivel tecnológico. Tercero, 'el despegue', período cuyo crecimiento es rápido, la expansión de algunos sectores son guías y donde la tecnología que se aumentó se aplica, creando así una tendencia de autosuficiencia y con una tasa de inversión neta superior a más del 10\%. Cuarta, 'marcha hacia la madurez', situación en la que la tecnología se aplica en su conjunto, ejerce cambios estructurales y pueden aparecer nuevos sectores estratégicos que reemplazan a los que estuvieron presentes en la etapa de 'despegue', cuyo objetivo es mantener la tasa de crecimiento. Finalmente, 'el alto consumo de masas', la cual se caracteriza por el sector servicios, el cual es dominante en la estructura económica y hay un aumento en la producción de bienes de consumo durable y de primera necesidad (Slater, 2011).

OASIS, ISSN: 1657-7558, E-ISSN: 2346-2132, Nº 32, Julio - Diciembre de 2020, pp. 85-104 


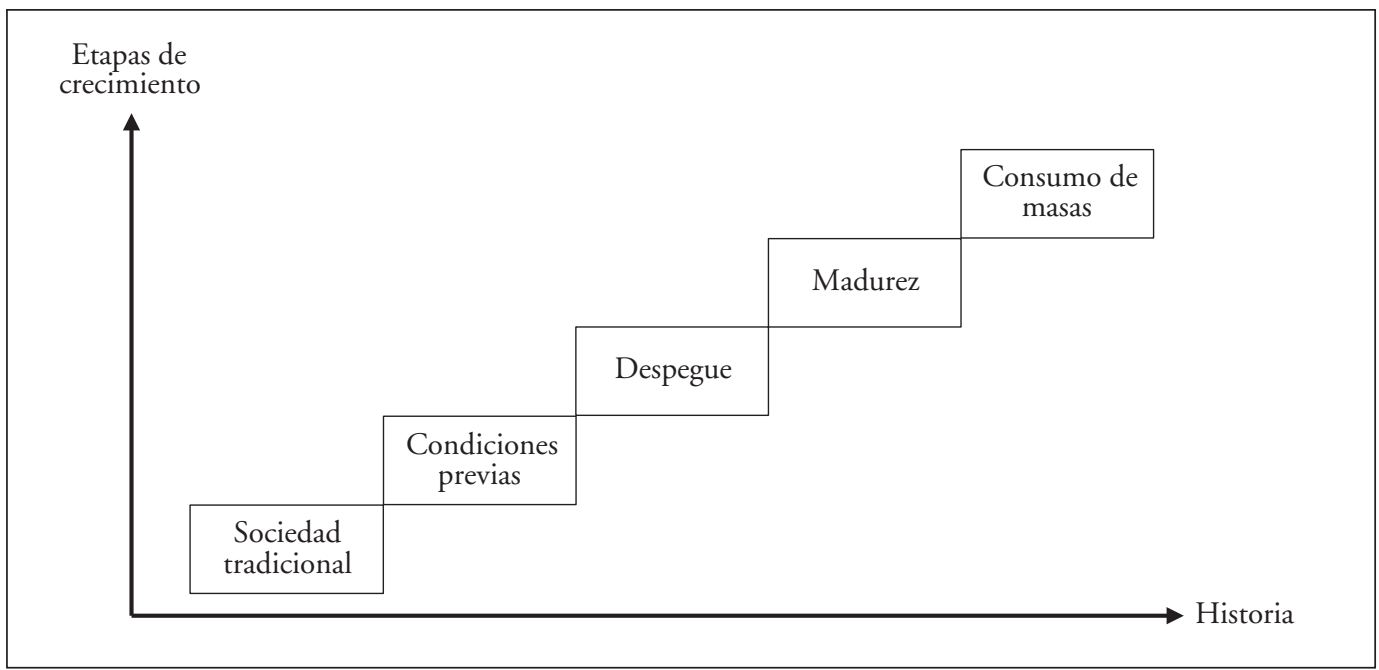

Fuente: (Slater, 2011)

Según Rostow, el punto de partida de los países es la sociedad tradicional, pero que con el tiempo y la aplicación de diferentes medidas económicas que activen sectores estratégicos de la economía, la nación podría iniciar el ascenso de la escalera del desarrollo, logrando así alcanzar a los países desarrollados, como se evidencia en la ilustración 2 (Taylor \& Flint, 2002). No obstante, él analiza los países de manera individual, pero dejando claro que -desde el siglo XVI- los países cada vez están más entrelazados, luego el estudio del desarrollo debe ser integrado y no individualista. Asimismo, olvida que no todos los países inician en el mismo punto y que el desequilibrio del desarrollo no se debe a que las naciones van a un ritmo de avance distinto. Por el contrario, el hecho de que algunos países sean ricos y otros pobres se debe a un cúmulo de hechos históricos y a un sistema productivo capitalista que los han establecido en esos complejos productivos con sus propios procesos de desarrollo y subdesarrollo, como lo establece Wallerstein (Taylor \& Flint, 2002).

Es así como la estructura del sistema internacional seguirá siendo establecida por el desarrollo económico del capitalismo, con sus debidas transformaciones en el tiempo y el espacio. Los países de centro continuarán compitiendo por conquistar mercados para la venta de los productos de sus multinacionales en los países periféricos y de nuevos sectores económicos estratégicos como son la ciencia y la tecnología, los cuales, como antes se explicó, requieren de altas sumas de inversión, y que fortalecerán con mayor ahínco el sector financiero y especulativo. Asimismo, los Estados aumentarán su capacidad de acción en el sistema internacional en la medida que puedan 


\section{Ilustración 2}

El desarrollismo

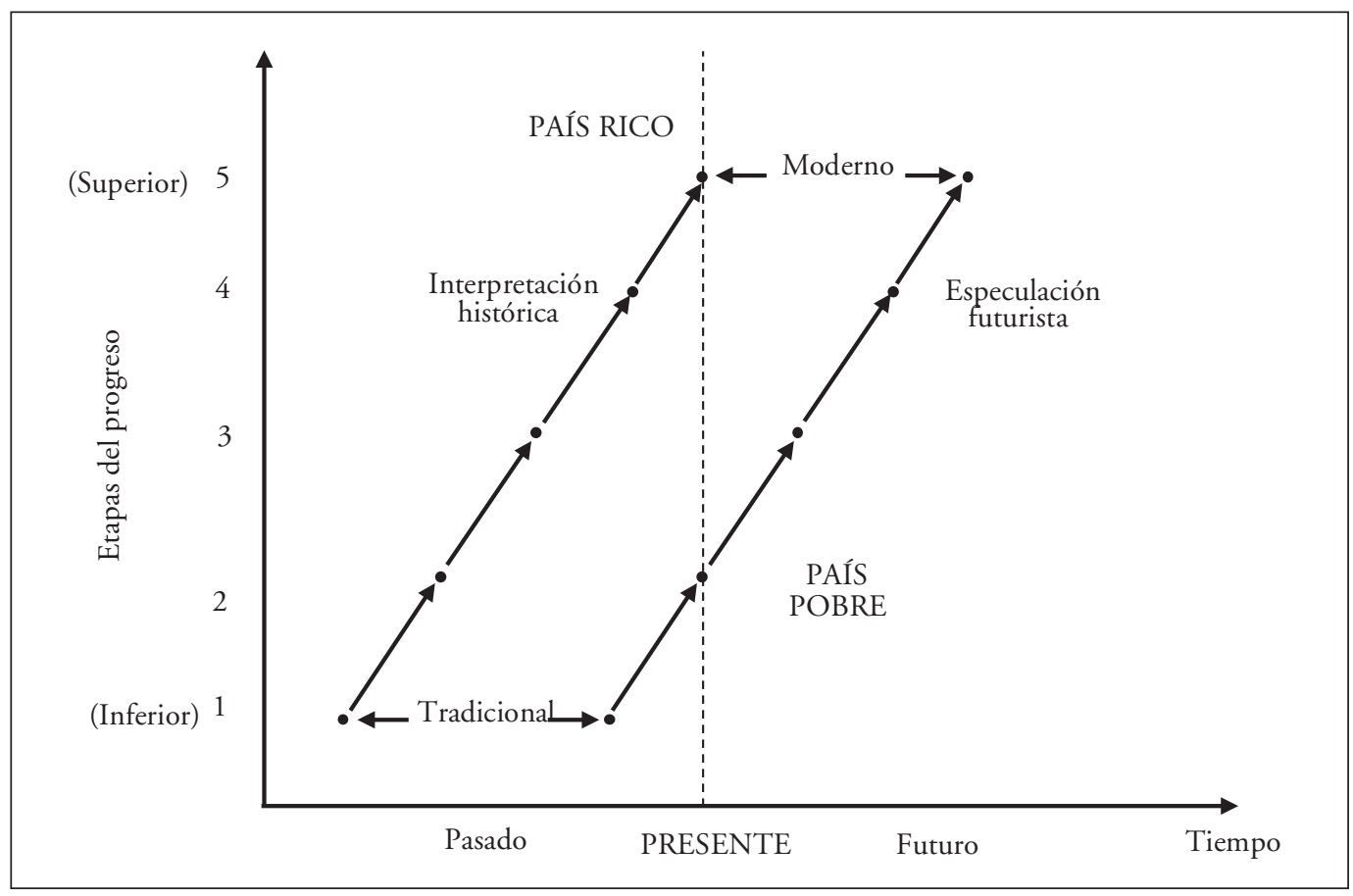

Fuente: (Taylor \& Flint, 2002)

constituir empresas que estén a la vanguardia de los sistemas de información para así determinar el funcionamiento de las sociedades y el control de la población.

Finalmente, si bien en este acápite se menciona constantemente la relación entre los países centro y la periferia, siendo los primeros los principales actores con mayor probabilidad para determinar la economía en el siglo Xxi, no se puede desconocer tampoco la actuación de los países semiperiféricos que se han convertido en agentes de suma importancia para la configuración económica del sistema internacional ya que tienen la posibilidad de establecer condiciones a los países de centro. Esta situación lleva a que ciertos países semiperiféricos puedan confrontar a una escala internacional, de manera sostenida y a un nivel suficiente, al país centro, creando un conflicto incierto incluso si la nación dominante dispone y utiliza sus recursos de manera efectiva y apropiada (Szayna, y otros, 2001). Por consiguiente, durante los siguientes años, es necesario analizar la actuación del sistema productivo capitalista en estos países, ya que estas naciones son las que están concentrando un alto porcentaje de las dinámicas de la cuarta revolución. 


\subsubsection{Relación entre agentes del sistema internacional}

Las teorías dominantes de las relaciones internacionales desde sus orígenes como disciplina han considerado que el actor principal es el Estado, de ahí que el realismo, neorrealismo y algunas tendencias del paradigma liberal centren sus estudios exclusivamente en estudiar el comportamiento de esta unidad. No obstante, por las dinámicas de la vida internacional han surgido nuevos actores que juegan un papel fundamental para mantener el statu quo del orden internacional, verbigracia: las organizaciones intergubernamentales (OIG) que han creado regímenes internacionales (FrassonQuenoz, 2014), o unidades que están determinando, de manera indirecta, la estructura internacional, por ejemplo, las multinacionales o compañías transnacionales.

En el marco de lo anterior, Robert Gilpin fue unos los primeros estudiosos en acercarse a los temas de economía internacional dentro de la disciplina de las relaciones internacionales. En The Political Economy of International Relations (1987) evidencia la importancia que las multinacionales tomaban para esa época, lo que abría la puerta a considerar nuevos agentes que podían influir en el sistema internacional. A pesar de abordar las multinacionales y su envergadura en la configuración económica del orden mundial, mantuvo el enfoque estatista sosteniendo que los Estados seguían siendo los agentes más importantes dentro del sistema internacional ya que eran estos los que hacían las reglas del ordenamiento mundial (Gilpin, 2001).
Durante estos últimos tres decenios, no obstante, la situación ha cambiado. Las compañías multinacionales, junto con la economía, han ganado un mayor rol en el sistema internacional y se han convertido en actores de suma importancia, al punto de tener capacidad para influir en la agenda política, como sucede en Estados Unidos, y dejando de lado en muchas ocasiones las demandas del ciudadano del común (Delsol, 2015). Asimismo, con el fin de lograr los objetivos del sistema productivo capitalista se estableció una relación simbiótica entre el Estado y las grandes corporaciones, alianza que les permitiría a los dos agentes del sistema tener mayor capacidad de acción dentro del orden internacional y ganar de manera simultánea.

Para ilustrar de mejor forma la relación entre estos dos agentes del sistema internacional se puede estudiar el concepto de inteligencia económica, el cual fue elaborado por François Fillon, ex primer ministro del gobierno de Nicolás Sarkozy, quien en 2011, bajo la circular no $5554 /$ sG, lo definió como la actividad que consiste:

(...) en recolectar, analizar, dar valor, difundir y proteger la información económica estratégica, a fin de reforzar la competitividad del Estado, una compañía o un establecimiento de investigación [agregando además que] la política económica de Francia constituye uno de los apartados de la política económica global. Contribuye al crecimiento, así como al apoyo del empleo sobre el territorio nacional, preservando la competitividad y la seguridad de las empresas francesas y de los establecimientos públicos de investigación. 
De igual forma, sentencia que los objetivos de acción del Estado deben estar direccionados por tres ejes, a saber: 1. Asegurar una vigilancia estratégica que facilite la toma de decisiones de los actores públicos en materia económica. 2. Sostener la competitividad de las empresas y la capacidad de transferencia de tecnología de las entidades de investigación en prioridad para el provecho de las empresas francesas y europeas. 3. Garantizar la seguridad económica de las empresas y organismos de investigación (Fillon, 2011).

Si bien este ejemplo se enfoca en el Estado francés, este tipo de estrategias son aplicadas por las potencias -en general- $y$ han estado presentes durante la historia de los países que ordenan el sistema internacional, ya que estas para mantener su poder de influencia en la vida internacional fortalecen sus sectores económicos que determinan el comportamiento de los agentes del orden global. Lo anterior, lo evidencia el economista surcoreano Ha-joon Chang quien en su texto Patada a la escalera: la verdadera historia del libre comercio, evidencia cómo los países que se encuentran en la parte superior de la jerarquía del orden global han construido diferentes normas para que países con menores capacidades económicas, políticas y diplomáticas y más necesitados o vulnerables adopten medidas que no siempre están destinadas a su beneficio (Chang, 2013). Así, el papel que juega el Estado es ayudarle a garantizar a sus corporaciones conquistar nuevos mercados, de ahí que, su cuerpo diplomático estará a la disposición para que en la nueva estandarización de los tratados de libre comercio le permita adquirir más capacidades de acción dentro de la configuración mundial.
En ese sentido, para comprender la vida internacional y el comportamiento de sus agentes, en el siglo xxI, es necesario estudiar con precisión la interacción y el rol de los agentes dentro del sistema que tienen mayor capacidad de actuar. A saber, el Estado y las multinacionales. También es necesario un análisis sobre sus dinámicas en el tiempo y las que puedan percibirse con las nuevas innovaciones de la cuarta revolución, pues se avizora un panorama distinto, ya que las corporaciones cada vez están determinando más el comportamiento económico y de las sociedades (Harari, 2016). En otras palabras, la importancia que las empresas multinacionales tienen se refleja no solo en términos económicos, sino también en la determinación de los elementos constitutivos y comportamentales de las sociedades, ya que mientras en el siglo xx eran los líderes políticos (como Harry Truman, Charles de Gaulle, Winston Churchill o Joseph Stalin, entre otros) los que determinaban los comportamientos de sus conciudadanos, en la actualidad, son las corporaciones de la tecnología (Facebook, Google, Instagram, entre otras) las que establecen estos parámetros.

\subsubsection{Instituciones internacionales y derecho internacional}

Como ya se mencionó, el sistema internacional está establecido, regulado y sostenido a través de normas, las cuales han sido creadas por los humanos y sus colectivos. Estas son de carácter social y que, de manera consciente, buscan regular sus relaciones sociales. Teniendo claro lo anterior, se debe agregar que estas disposiciones normativas solo las pueden establecer los acto- 
res que han adquirido poder o las capacidades suficientes para incidir en ellas, estableciendo así elementos que les puedan favorecer.

Ahora bien, el estudio de las instituciones internacionales en las relaciones internacionales toma fuerza con el surgimiento de la Organización de las Naciones Unidas (ONU), sus agencias, otras OIG y la expansión del comercio y el capitalismo financiero. Esto ha motivado a los estudiosos a desarrollar teorías para acercarse a estos nuevos organismos del orden mundial. Para los realistas, las instituciones internacionales son una herramienta más de los Estados que les otorga poder en las dinámicas internacionales ya que, a través de estas, logran cumplir sus objetivos y metas establecidas. Contrario a lo anterior, el paradigma liberal y sus ramas (institucional, neoliberal, interdependencia y republicana), desarrollan a estos actores de la vida internacional. En las definiciones ofrecidas por esta tendencia académica, se evidencia que las instituciones tienen un carácter de ordenador del sistema internacional, ya que los Estados les otorgan cierto poder para que estas instituciones desarrollen y hagan cumplir las normas establecidas en la configuración mundial (Frasson-Quenoz, 2014). De ahí que, la cooperación y la interdependencia entre los actores se desarrollen con plenitud y mantengan el statu quo en el tiempo.

No obstante, si bien las posturas del liberalismo describen el accionar de los Estados y las organizaciones internacionales de manera optimista y positiva para todos los actores, la realidad es que las instituciones y el derecho internacional tampoco se escapan de la naturaleza del ordenamiento económico. La eco- nomía estructura el ordenamiento jurídico y político del sistema internacional, de ahí que las organizaciones y el derecho internacional tienen como objetivo justificar y garantizar el funcionamiento del sistema productivo capitalista (Krippendorff, 1985).

Para comprender mejor lo anterior, la clasificación ofrecida por Anghie, Koskenniemi y Orford (2016), establece dos métodos para conceptualizar las instituciones internacionales, el actuar de los Estados en ellas y el derecho internacional. De acuerdo con estos autores, el primer enfoque se evidencia en la teoría liberal, que a pesar de reconocer la asimetría en el poder y las limitaciones de los Estados, utiliza una postura restringida ya que contempla las instituciones y el derecho como una herramienta técnica, su visión es optimista y entiende el derecho como un ordenamiento justo e idóneo para que todos los agentes del sistema internacional lleguen a consensos en temas relacionados con la seguridad, el comercio internacional y el medio ambiente (Anghie, Koskenniemi \& Orford, 2016). Asimismo, esta aproximación considera que las prácticas imperialistas de las grandes potencias y el accionar imponente de los países con mayores capacidades es una cuestión del pasado, ya que según esta visión, el imperialismo estuvo presente en el período comprendido entre finales del siglo xvi y la primera mitad del xx, siendo el proceso de descolonización, que alcanzó su cúspide con la "Declaración sobre la concesión de la independencia de los países y pueblos coloniales", el que finalizó ese período de la historia y que reforzó "la Declaración universal de los derechos del hombre y el ciudadano", 
cumpliendo así los preceptos de Immanuel Kant con su obra Sobre la paz perpetua (Anghie, Koskenniemi \& Orford, 2016).

La segunda clasificación de estos autores es la postura amplia, la cual considera que aun el pasado imperial tiene consecuencias y efectos estructurales sobre el derecho internacional y sus instituciones. Para este enfoque, el imperialismo todavía prevalece pero de una manera distinta a la del pasado, ya que el imperialismo clásico, conocido por sus colonias, estuvo marcado por tres justificaciones: primero, las políticas imperiales que buscaban expandir sus mercados hacia la periferia y obtener materias primas para asegurarse una competencia eficaz frente a las otras naciones europeas que estaban compitiendo; segundo, la "necesidad" de asegurar una esfera de influencia sobre aquellos territorios que tenían no solo un valor económico sino también geoestratégico para el control de las rutas comerciales; finalmente, para justificar estas acciones las potencias elaboraron un discurso civilizatorio, el cual consistía en educar, modernizar y mejorar la periferia al momento de estandarizarla con conocimientos, administración pública y desarrollo económico (Anghie, Koskenniemi \& Orford, 2016). En ese sentido, las acciones imperialistas estuvieron acompañadas por el derecho internacional, el cual presentó un lenguaje y una arquitectura internacional para que los países pudieran negociar, tomar posesión de territorios, establecer un sistema de intercambio financiero, de materias primas $\mathrm{y}$ de productos industriales, ofreciendo de esta manera ventajas a los países de centro.
No obstante, la forma como se expresa el imperialismo ha cambiado desde la segunda mitad del siglo xx. Ha tomado un enfoque más amplio, el cual se materializa no solo con la consolidación de los monopolios y las finanzas, como antes se explicó, sino también con las instituciones y el derecho internacional ya que estas permiten que los países desarrollados establezcan estándares internacionales para calificar el nivel de competencia de las poblaciones periféricas y así decretar un modelo para que estos lo apliquen, lo que llevaría a que las inversiones de las naciones desarrolladas se garanticen en estos países (Anghie, Koskenniemi $\&$ Orford, 2016).

Ahora bien, entendiendo que el derecho internacional y las instituciones se han desarrollado con base en los intereses de los Estados que tienen mayor capacidad para influir dentro de la arquitectura global y que se ha establecido con el fin de garantizar el funcionamiento del sistema productivo; para comprender las instituciones y el derecho internacional, en el siglo XXI, es necesario poner atención durante los años venideros qué países elaborarán las normas internacionales y cómo las establecerán, más específicamente en temas como las finanzas, verbigracia las criptomonedas y Blockchain, la creación y consolidación de las compañías que surjan con la cuarta revolución y la regulación de asuntos como la inteligencia artificial y el ciberespacio. De seguro, los países semiperiféricos, con los nuevos cambios del capitalismo, tendrán mucho que aportar a esta nueva normatividad internacional, ya que estos países están compitiendo en las anteriores ramas con los países de centro, de ahí que surja el inconformismo de las potencias de centro que 
en la actualidad de están viendo desplazadas y han tenido que compartir su poder dentro de la configuración internacional.

\section{COMENTARIOS FINALES}

En un contexto de turbulencia y de cambios profundos en la configuración del sistema internacional, la disciplina de las relaciones internacionales conmemora su primer siglo de natalicio, de ahí que sea necesario no solo evaluar las teorías que se han esbozado en este tiempo para explicar esta parcela de la realidad de los humanos y sus sociedades, sino también de tratar de conceptualizar los nuevos elementos para comprender los cambios que traerá consigo el siglo XxI.

En el marco de lo anterior es que se esboza el presente trabajo y la agenda académica de este capítulo. En consecuencia, se utilizó un enfoque ontológico y epistemológico materialista para comprender la realidad en la que están inscritas los agentes del sistema internacional y cuya variable principal es el sistema productivo capitalista, evidenciando así que este modo de producción aún mantiene su influencia en las esferas político, militar y cultural, y que seguirá afectando a estas categorías en la medida como el capital se comporte en esta nueva era. Asimismo, se establecieron elementos para comprender las relaciones económicas en el siglo XxI, haciendo hincapié en la inversión extranjera directa, los sectores productivos que están marcando el mercado global, como son la ciencia y la tecnología, y la competencia que se avizora entre los países de centro y semiperiferia para establecer la nueva normatividad en estos sectores.
De igual manera, el estructuralismo económico sigue vigente para comprender un gran porcentaje de la realidad material de las relaciones internacionales. No obstante, se deja la puerta abierta para que, en los próximos años, de acuerdo con los avances de la ciencia y las consecuencias que traigan estos y la evolución del capitalismo para la conformación y comportamiento de las sociedades y los seres humanos, se sigan revaluando los principios de este enfoque de las relaciones internacionales. De ahí que este capítulo es el principio de una agenda académica ya que aún falta trabajar en temas como el comportamiento de la semiperiferia, las potencias regionales y la lucha por el control del capital en el siglo xxI.

\section{REFERENCIAS}

Anghie, A.; Koskenniemi, M. \& Orford, A. (2016). Imperialismo y derecho internacional. Bogotá, Colombia: Siglo del Hombre Editores.

Arenal, C. d. (04-06/1989). La teoría de las relaciones internacionales hoy: debates y paradigmas. Estudios Internacionales(86), 153-182.

Aron, R. (1946). Introducción a la filosofia de la historia. Buenos Aires, Argentina: Losada S.A.

Aron, R. (1975). Las etapas del pensamiento sociológico. Buenos Aires, Argentina: Siglo xx.

Aron, R. (1996). Lecciones sobre la historia. Cursos del Collège de France. Ciudad de México D.F., México: Fondo de Cultura Económica.

Baños, P. (2018). Así se domina el mundo. Desvelando las claves del poder mundial. Barcelona, España: Planeta.

Barnes, B. (1990). La naturaleza del poder. Barcelona, España: Pomares Corredor. 
Castells, M. (1996). La era de la información. Economía, sociedad y cultura. Madrid, España: Alianza Editorial, S.A.

Cervera, R. C. (1991). Relaciones internacionales. Madrid, España: Ediciones de la Ciencia.

Chang, H.-J. (01-06/2013). Patada a la escalera: la verdadera historia del libre comercio. Ensayos de Economía(42), 27-57.

Conferencia de las Naciones Unidas sobre Comercio y Desarrollo. (2018). Informe sobre las inversiones en el mundo 2018. La inversión y las nuevas políticas industriales. Mensajes clave y panorama general. Conferencia de las Naciones Unidas sobre el Comercio y el Desarrollo.

Cox, R. W. (1981). Social Foreces, States and World Order: Beyond International Relations Theory. $\mathrm{Mi}$ llennium Journal of International Studies, 126-155.

Delsol, C. (2016). Populismos: una defensa de lo indefendible. Bogotá: Editorial Ariel.

Duroselle, J.-B. (2018). El estudio de las relaciones internacionales: Objeto, método, perspectivas. Relaciones Internacionales(37), 173-191.

Fillon, F. (2011). Action de l'État en matière d'intelligence économique. Paris: circulaire $n^{\circ}, 5554$.

Frasson-Quenoz, F. (2014). Autores y teorías de relaciones internacionales: Una cartografía. Bogotá, Colombia: Universidad Externado de Colombia.

Gilpin, R. (2001). Global Political Economy. Understanding the International Economic Order. New Jersey, Estados Unidos: Princeton University Press.

Greene, R. (2018). The laws of human nature. Nueva York, Estados Unidos: Viking.

Grosser, R. U. (2011). La naturaleza sistémica de la actual crisis económica internacional. En Enfoques sobre el origen de la crisis mundial del 2008. Bogotá, Colombia: Academia Colombiana de Ciencias Económicas.
Harari, Y. N. (2016). Homo Deus. Breve historia del mañana. Bogotá, Colombia: Debate.

Hobson, J. \& Lenin, V. (2009). Imperialismo. Madrid, España: Capitán Swing Libros.

Holsti, K. (02/1964). The Concept of Power in the Study of International Relations. Background, 7(4), 179-194.

Holsti, K. (1983). International Politics. A framework for analysis. New Jersey, Estados Unidos: PrenticeHall International.

Jacobo, A. F. (2011). La escuela de Fráncfort: la emancipación mediante la recuperación del humanismo original del marxismo. Bogotá, Colombia: Universidad de los Andes.

Jerez, U. C. (2007). El materialismo filosófico: Historia y esencia. Bogotá, Colombia: Escuela ideológica.

King, G.; Keohane R.O. \& Verba, S. (2000). El diseño de la investigación social. La inferencia cientifica en los estudios cualitativos. Madrid, España: Alianza Editorial.

Krippendorff, E. (1985). Las relaciones internacionales como ciencia. Introducción. México D.F., México: Fondo de Cultura Económica.

Landes, H. (2016). Allô Houston! Les États-Unis vus par un américain en colère. Paris, Francia: Max Milo.

Mearsheimer, J. J. \& Walt, S. M. (2013). Leaving theory behind: Why simplistic hypothesis testing is bad for international relations. European Journal of International Relations, 19(3), 427-457.

Moscovici, P.; Montebourg, A.; Cahuzac, J. \& Pellerin, F. (2013). Mission d'expertise sur la fiscalité de l'économie numérique. Ministère de l'Économie et des Finances \& Ministère du Redressement Productif, Paris.

Prebisch, R. (1983). La crisis del capitalismo y la periferia. Estudios Internacionales (62), pp. 169-179. 
Prebisch, R. (1986). El desarrollo económico de la América Latina y algunos de sus principales problemas. Desarrollo Económico, 26(103), pp. 479-502.

Russell, B. (1953). Los problemas de la filosofia. Barcelona, España: Editorial Labor S.A.

Slater, F. (2011). Las etapas del crecimiento económmico de Rostow. Consideraciones sobre el evolucionismo como modelo interpretativo. Soñando el Sur (2), 114-121.
Szayna, T.; Byman, D.; Bankes, S.; Eaton, D.; Jones, S.; Mullins, R.; Lesser, I. \& Rosenau, W. (2001). The emergence of peer competitors. A framework for analysis. Santa Monica, Estados Unidos: RAND.

Taylor, P. \& Flint, C. (2002). Geografia politica. Economia-mundo, Estado-nación y localidad. Madrid, España: Trama Editorial.

Wallerstein, I. (1999). El capitalismo ¿quées? Un problema de conceptualización. Ciudad de México, México: Universidad Nacional Autónoma de México. 